\title{
Tobacco smoking and associated factors in human immunodeficiency virus-infected adults attending human immunodeficiency virus clinics in the Western Cape province, South Africa
}

\begin{tabular}{|c|c|}
\hline \multicolumn{2}{|c|}{$\begin{array}{l}\text { Authors: } \\
\text { Muyunda Mutemwa }{ }^{1} \text { (D) } \\
\text { Nasheeta Peer }^{1,2} \\
\text { Anniza de Villiers }^{3} \\
\text { Mieke Faber }^{1} \text { (D) } \\
\text { Andre-Pascal Kengne }^{1,2}\end{array}$} \\
\hline \multicolumn{2}{|c|}{$\begin{array}{l}\text { Affiliations: } \\
{ }^{1} \text { Non-Communicable } \\
\text { Diseases Research Unit, } \\
\text { South African Medical } \\
\text { Research Council, Cape Town, } \\
\text { South Africa }\end{array}$} \\
\hline \multicolumn{2}{|c|}{$\begin{array}{l}{ }^{2} \text { Department of Medicine, } \\
\text { University of Cape Town, } \\
\text { Cape Town, South Africa }\end{array}$} \\
\hline \multicolumn{2}{|c|}{$\begin{array}{l}{ }^{3} \text { Research Capacity } \\
\text { Development Division, } \\
\text { South African Medical } \\
\text { Research Council, Cape } \\
\text { Town, South Africa }\end{array}$} \\
\hline \multicolumn{2}{|c|}{$\begin{array}{l}\text { Corresponding author: } \\
\text { Andre Kengne, } \\
\text { andre.kengne@mrc.ac.za }\end{array}$} \\
\hline \multicolumn{2}{|c|}{$\begin{array}{l}\text { Dates: } \\
\text { Received: } 15 \text { Jan. } 2020 \\
\text { Accepted: } 14 \text { Feb. } 2020 \\
\text { Published: } 21 \text { Apr. } 2020\end{array}$} \\
\hline \multicolumn{2}{|c|}{$\begin{array}{l}\text { How to cite this article: } \\
\text { Mutemwa M, Peer N, } \\
\text { De Villiers A, Faber M, } \\
\text { Kengne AP. Tobacco smoking } \\
\text { and associated factors in } \\
\text { human immunodeficiency } \\
\text { virus-infected adults attending } \\
\text { human immunodeficiency } \\
\text { virus clinics in the Western } \\
\text { Cape province, South Africa. } \\
\text { S Afr J HIV Med. 2020;21(1), } \\
\text { a1072. https://doi.org/ } \\
\text { 10.4102/sajhivmed.v21i1.1072 }\end{array}$} \\
\hline \multicolumn{2}{|l|}{ Read online: } \\
\hline 回保品 & $\begin{array}{l}\text { Scan this QR } \\
\text { code with your } \\
\text { smart phone or } \\
\text { mobile device } \\
\text { to read online. }\end{array}$ \\
\hline
\end{tabular}

Background: In human immunodeficiency virus (HIV)-infected individuals, smoking increases both HIV-related and non-related negative health outcomes.

Objectives: To determine the prevalence and associations of smoking in HIV-infected adults receiving antiretroviral therapy at public healthcare facilities in the Western Cape province, South Africa.

Methods: Participants comprised 827 HIV-infected patients, who were $>18$ years old and randomly selected from $17 \mathrm{HIV}$ healthcare facilities. Self-reported smoking was defined as smoking tobacco daily or occasionally. Serum cotinine levels confirmed smoking status.

Results: Participants included 653 women and 174 men. The overall mean (standard deviation [SD]) age was 38.9 (9.0) years, $41.1(8.9)$ years in men and 37.7 (8.9) years in women $(p<0.001)$. The median diagnosed duration of HIV infection was 5 years. Smoking prevalence was $22 \%$ overall, and $26 \%$ in men and $21 \%$ in women $(p=0.022)$. The prevalence of former smoking was $14 \%$. About a quarter of participants $(185 / 751 ; 24.6 \%)$ had serum cotinine levels $>100 \mathrm{mg} / \mathrm{mL}$ with similar prevalence of high levels across smoking status (current smokers: $27.2 \%$, former smokers: $29.6 \%$ and never smokers: $22.7 \%, p=0.564$ ) and did not vary by age, gender, cluster of differentiation 4 count or known duration of HIV. There was no agreement between self-reports and cotinine levels at ranking smoking exposure.

Conclusions: Prevalence of current tobacco smoking in HIV-infected patients on care is within the range of that in the general population. This highlights the potential missed opportunity or challenges of co-addressing smoking cessation in individuals already in regular contact with the health system.

Keywords: HIV and AIDS; smoking; cotinine; prevalence; South Africa.

\section{Introduction}

Globally, over 1.1 billion men and women $\geq 15$ years of age currently smoke tobacco. Consequently, tobacco use is a growing public health burden worldwide that was responsible for 7.1 million deaths in 2016. ${ }^{1}$ Even in South Africa (SA), despite the introduction of comprehensive legislative action to discourage tobacco use since the early 1990s, tobacco smoking remains a major public health problem. ${ }^{2}$ In $2016,37 \%$ of men and $8.0 \%$ of women $\geq 15$ years of age smoked tobacco. ${ }^{3}$ Tobacco smoking contributes to a large burden of the preventable disease accounting for $8.0 \%-$ $9.0 \%$ of mortality in SA. ${ }^{2}$ While lung cancer had the largest attributable fraction because of tobacco smoking, cardiovascular diseases contributed to the largest proportion of deaths caused by smoking.

The impact of smoking extends beyond the well-known consequences of tobacco use to other conditions including human immunodeficiency virus (HIV) infection. In people living with HIV or acquired immunodeficiency syndrome (AIDS) (PLWHA), the harmful effects of smoking are greater and threaten efforts in controlling HIV and AIDS. ${ }^{1}$ Smoking increases both HIV-related and non-related outcomes and has been shown to impact HIV disease progression. ${ }^{4,5}$ Nevertheless,

Copyright: @ 2020. The Authors. Licensee: AOSIS. This work is licensed under the Creative Commons Attribution License. 
smoking prevalence in PLWHA is approximately twofold to threefold higher than in the general population in developed countries and ranges from $40 \%$ to $74 \%{ }^{6,7}$

The greater adverse effects of tobacco smoking in PLWHA are highly relevant to SA. The country has the greatest burden of HIV worldwide with approximately 7.97 million PLWHA in 2019. ${ }^{8}$ With almost $20 \%$ of $15-49$-year-old South African adults being HIV positive, determining the burden of tobacco smoking in the HIV infected can inform strategies for tobacco cessation in this high-risk population. This is particularly pertinent in the era of widespread dissemination of antiretroviral therapy (ART) in $\mathrm{SA}^{9}$ and increased longevity of the HIV-infected population. People living with HIV and AIDS are now at an increased risk of dying from cardiovascular and other non-communicable diseases (NCDs), including tobacco-related conditions, rather than from AIDS. ${ }^{10,11,12}$

This study, therefore, aims to determine the prevalence of smoking and associated factors including HIV-specific factors in PLWHA receiving ART at public healthcare facilities in the Western Cape province of SA.

\section{Methods}

\section{Population and sampling}

This cross-sectional study was conducted in a sample of $\geq$ 18-year-old HIV-infected adults who were randomly selected from a list of patients attending the clinic on the study day. Participants were recruited between March 2014 and February 2015 from healthcare facilities in the Western Cape that provided ART to at least $325 \mathrm{HIV}$-infected patients per month. This was to ensure the recruitment of an adequate number of participants within a reasonable period. Of the 17 healthcare facilities selected, 10 were in Cape Town and seven were in the surrounding rural municipalities. Excluded participants were those who were pregnant, breastfeeding, bedridden, undergoing cancer treatment, on corticosteroid treatment, or unwilling or unable to provide consent. The detailed methods have been described previously. ${ }^{13}$

\section{Data collection}

Trained clinicians, nurses and fieldworkers collected data via standardised international questionnaires, clinical measurements and biochemical analyses. Data were captured on personal digital assistants (PDAs), using electronic case report forms with built-in checks for quality control. The interviews and physical examinations were conducted on the recruitment day, and following an overnight fast, participants returned the next day to have their blood samples taken.

Participants provided their socio-demographic history, including tobacco use, which was adapted from the World Health Organization's (WHO) STEPwise approach to Surveillance (STEPS) tool. ${ }^{14}$ Information on the duration of diagnosed HIV infection, cluster of differentiation 4 (CD4) counts and ART regimens was extracted from clinical records. Height to the nearest millimetre was measured using a Leicester Height Scale (Seca, UK) with the participant barefoot and in the upright position. Weight to the nearest gram was measured using Analog and Digital (A\&D) Medical PersonalScale (Model UC-321, Japan) with the participant in light clothes and without shoes. Biochemical analyses included serum cotinine levels and lipid profiles, which were acquired at an ISO 15189-accredited pathology laboratory (Path Care, Reference Laboratory, Cape Town, SA), as previously described in detail. ${ }^{15}$

\section{Definitions}

Participants were classified as either 'current smoker', 'former smoker' or 'never a smoker', considering all forms of smoked tobacco, including cigarettes, cigars or pipes. Current smokers included participants who smoked daily or occasionally. Former smokers refer to participants who indicated that they had quit smoking at the time of the interview, regardless of the duration since quitting. 'Smokeless tobacco users' referred to the use of chewing tobacco, snuff or betel leaf and the areca nut at the time of the survey. Exposure to second-hand smoke was determined from 'household smoke'. Cotinine, a major metabolite of nicotine, is commonly used as a biomarker to identify exposure to tobacco. ${ }^{16,17}$ Serum cotinine levels were used to define the different smoking categories as follows: 'no tobacco exposure': cotinine $<10 \mathrm{mg} / \mathrm{mL}$, 'environmental smoke exposure or light smoking': cotinine levels of $10 \mathrm{ng} / \mathrm{mL}-$ $100 \mathrm{ng} / \mathrm{mL}$ and 'moderate to heavy smoking': cotinine $>100 \mathrm{mg} / \mathrm{mL}$, in line with the 2012 South African National Health and Nutrition Examination Survey (SANHANES). ${ }^{18}$

Alcohol use was defined as drinking at least one standard alcoholic drink per day. A standard alcoholic drink consists of a can $(340 \mathrm{~mL})$ of beer, one glass $(125 \mathrm{~mL})$ wine or 'one-

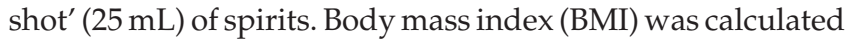
as weight in kilograms divided by height in metres squared $\left(\mathrm{kg} / \mathrm{m}^{2}\right)$, and overweight and obesity was defined as BMI $\geq$ $25 \mathrm{~kg} / \mathrm{m}^{2} .{ }^{19}$ Cut-points for HIV-related variables were set at median values, that is, $\geq 396 \mathrm{cell} / \mathrm{mm}^{3}$ for $\mathrm{CD}^{+}$counts and of $\geq 5$ years duration of HIV diagnosis.

\section{Statistical analysis}

The Statistical Package for Social Sciences (IBM SPSS Inc, Chicago, IL, USA) V.25.0 software was used for the data analyses. Continuous variables are presented as means ( \pm standard deviation [SD]) or medians (25th - 75th percentiles) and categorical variables are presented as counts and percentages. Analysis of variance (ANOVA), $\chi^{2}$ tests and non-parametric equivalents were used as appropriate for group comparisons. Logistic regression models adjusted for age and gender were used to determine associations with current smoking. A $p$-value $<0.05$ defined statistically significant results.

\section{Approval to conduct the study}

Permission to conduct the survey was obtained from the Health Research Office of the Western Cape Department of Health and the relevant healthcare facilities. The study was approved by the South African Medical Research Council Ethics Committee and conducted in accordance with the 
principles of the Declaration of Helsinki. All participants signed informed consent. Data were anonymised to prevent identification of individual participants.

\section{Ethical consideration}

Permission to conduct the survey was obtained from the Health Research Office of the Western Cape Department of Health and the relevant healthcare facilities. The study was approved by the South African Medical Research Council Ethics Committee (reference number: EC021-11/2013) and conducted in accordance with the principles of the Declaration of Helsinki. All participants signed informed consent.

\section{Results}

The sample for this analysis comprised 827 participants, 653 (79\%) women and $174(21 \%)$ men after the exclusion of four with missing information on smoking status. The mean age was 38.4 years overall, with men significantly older than women (41.1 vs. 37.7 years, $p<0.001$ ) (Table 1). Compared to men, women had fewer years of education, but a higher proportion was employed. Men were more likely to consume alcohol than women $(54.0 \%$ vs. $34.3 \%, p<0.001)$. Compared with men, women were more likely to have higher BMI and prevalence of overweight and obesity (both $p<0.001)$. Median duration of diagnosed HIV infection $(p=0.048)$ and median CD4 counts $(p=0.001)$ were also higher in women compared with men. The lipid profile did not vary by gender.

Current smoking prevalence was $22 \%$ overall and $26 \%$ in men and $21 \%$ in women ( $p=0.022$ ) (Table 1 and Figure 1). Overall, $14 \%$ of the participants were former smokers (Table 1). There were no significant trends in smoking status

TABLE 1: Characteristics of human immunodeficiency virus patients presented by gender and smoking status.

\begin{tabular}{|c|c|c|c|c|c|c|c|c|c|c|c|c|}
\hline \multirow[t]{2}{*}{ Variables } & \multicolumn{2}{|c|}{$\begin{array}{l}\text { Male patients } \\
(N=174 ; 21 \%)\end{array}$} & \multicolumn{2}{|c|}{$\begin{array}{l}\text { Female patients } \\
(N=653 ; 79 \%)\end{array}$} & \multirow[t]{2}{*}{$p$} & \multicolumn{2}{|c|}{$\begin{array}{l}\text { Current smoker } \\
(N=181 ; 22 \%)\end{array}$} & \multicolumn{2}{|c|}{$\begin{array}{l}\text { Former smoker } \\
(N=118 ; 14 \%)\end{array}$} & \multicolumn{2}{|c|}{$\begin{array}{c}\text { Never smoker } \\
(N=528 ; 64 \%)\end{array}$} & \multirow[t]{2}{*}{$p$} \\
\hline & $n$ & $\%$ & $n$ & $\%$ & & $n$ & $\%$ & $n$ & $\%$ & $n$ & $\%$ & \\
\hline Age in years, mean (SD) & 41.1 & 8.9 & 37.7 & 8.9 & $<0.001$ & 39.3 & 10.1 & 38.3 & 8.6 & 38.1 & 8.7 & 0.332 \\
\hline$\leq 34$ & 64 & 36.8 & 242 & 37.1 & 0.167 & 71 & 39.2 & 45 & 38.1 & 190 & 36.0 & 0.649 \\
\hline $35-44$ & 68 & 39.1 & 257 & 39.4 & - & 69 & 38.1 & 41 & 34.7 & 215 & 40.7 & - \\
\hline $45-54$ & 28 & 16.1 & 127 & 19.4 & - & 29 & 16.0 & 26 & 22.0 & 100 & 18.9 & - \\
\hline \multicolumn{13}{|l|}{ Education level } \\
\hline$\leq$ Grade 12 & 161 & 92.5 & 633 & 96.9 & 0.008 & 176 & 97.2 & 114 & 96.6 & 504 & 95.5 & 0.536 \\
\hline$>$ Grade 12 & 13 & 7.5 & 20 & 3.1 & - & 5 & 2.8 & 4 & 3.4 & 24 & 4.5 & - \\
\hline \multicolumn{13}{|l|}{ Occupation } \\
\hline Employed & 91 & 52.3 & 373 & 57.1 & 0.031 & 94 & 51.9 & 68 & 57.6 & 302 & 57.2 & 0.345 \\
\hline Unemployed & 46 & 26.4 & 109 & 16.7 & - & 42 & 23.2 & 26 & 22.0 & 87 & 16.5 & - \\
\hline Pensioners & 7 & 4.0 & 35 & 5.4 & - & 10 & 5.5 & 6 & 5.1 & 26 & 4.9 & - \\
\hline \multicolumn{13}{|l|}{ Marital status } \\
\hline Married & 37 & 21.3 & 119 & 18.2 & 0.516 & 39 & 21.5 & 21 & 17.8 & 96 & 18.2 & 0.305 \\
\hline Never married & 113 & 64.9 & 430 & 65.8 & - & 108 & 59.7 & 83 & 70.3 & 352 & 66.7 & - \\
\hline Divorced or separated & 19 & 10.9 & 70 & 10.7 & - & 21 & 11.6 & 12 & 10.2 & 56 & 10.6 & - \\
\hline Widowed & 5 & 2.9 & 34 & 5.2 & - & 13 & 7.2 & 2 & 1.7 & 24 & 4.5 & - \\
\hline Use of smokeless tobacco products & 4 & 2.3 & 14 & 2.1 & 0.901 & 1 & 0.6 & 3 & 2.5 & 14 & 2.7 & 0.237 \\
\hline Second-hand smoke & 78 & 44.8 & 384 & 58.8 & 0.001 & 103 & 56.9 & 59 & 50.0 & 300 & 56.8 & 0.383 \\
\hline Serum cotinine $(N=751)$ & - & - & - & - & - & - & - & - & - & - & - & 0.564 \\
\hline$<10 \mathrm{ng} / \mathrm{mL}$ & $91 / 152$ & 59.96 & $367 / 599$ & 61.3 & 0.940 & $95 / 158$ & 60.1 & $63 / 108$ & 58.3 & $300 / 485$ & 61.9 & - \\
\hline $10 \mathrm{ng} / \mathrm{mL}-100 \mathrm{ng} / \mathrm{mL}$ & $23 / 152$ & 15.1 & $85 / 599$ & 14.2 & - & $18 / 158$ & 11.4 & $17 / 108$ & 15.7 & $73 / 485$ & 15.1 & - \\
\hline$>100 \mathrm{ng} / \mathrm{mL}$ & $38 / 152$ & 25.0 & $147 / 599$ & 24.5 & - & $45 / 158$ & 28.5 & $28 / 108$ & 25.9 & $112 / 485$ & 23.1 & - \\
\hline Alcohol use & 94 & 54.0 & 224 & 34.3 & $<0.001$ & 76 & 42.0 & 45 & 38.1 & 197 & 37.3 & 0.535 \\
\hline LDL-C, mmol/L, median (25th -75 th percentiles) & 2.5 & $2.0-3.1$ & 2.5 & $2.1-3.1$ & 0.684 & 2.5 & $2.1-3.1$ & 2.4 & $2.0-2.8$ & 2.5 & 2.1-3.1 & 0.492 \\
\hline HDL-C, mmol/L, median (25th -75 th percentiles) & 1.2 & $1.0-1.4$ & 1.2 & $1.0-1.5$ & 0.925 & 1.2 & $1.0-1.5$ & 1.3 & $1.1-1.5$ & 1.2 & $1.0-1.5$ & 0.888 \\
\hline $\mathrm{BMI}$ in $\mathrm{kg} / \mathrm{m}^{2}$, median (25th -75 th percentiles) & 21.2 & 20.1-23.4 & 28.8 & 23.3-33.8 & $<0.001$ & 25.5 & 21.4-31.8 & 28.3 & 22.3-34.7 & 27.9 & $22.8-32.8$ & 0.504 \\
\hline Overweight or obese & 47 & 27.0 & 474 & 72.6 & $<0.001$ & 106 & 58.6 & 70 & 59.3 & 345 & 65.3 & 0.178 \\
\hline Duration in years, median (25th -75 th percentiles) & 4 & $2-8$ & 5 & $2-9$ & 0.048 & 6 & $3-10$ & 4 & $2-6$ & 5 & $2-9$ & 0.020 \\
\hline$<$ Median of 5 years & $80 / 159$ & 50.3 & $274 / 606$ & 45.2 & 0.254 & $81 / 168$ & 48.2 & $61 / 108$ & 56.5 & $212 / 489$ & 43.4 & 0.040 \\
\hline$\geq$ Median of 5 years & $79 / 159$ & 49.7 & $332 / 606$ & 54.8 & - & $87 / 168$ & 51.8 & $47 / 108$ & 43.5 & 277 & 56.6 & - \\
\hline CD4+ count, median ( 25 th -75 th percentiles) $(N=388)$ & 272 & $168-460$ & 413 & $248-616$ & 0.001 & 405 & $265-564$ & 442 & 239-706 & 373 & 218-604 & 0.528 \\
\hline$<$ Median of 396 cells $/ \mathrm{mm}^{3}$ & $39 / 55$ & 70.9 & $155 / 333$ & 46.5 & 0.001 & $43 / 85$ & 50.6 & $20 / 53$ & 37.7 & $131 / 250$ & 52.4 & 0.151 \\
\hline$\geq$ Median of 396 cells $/ \mathrm{mm}^{3}$ & $16 / 55$ & 29.1 & $178 / 333$ & 53.5 & - & $42 / 85$ & 49.4 & $33 / 53$ & 62.3 & $191 / 250$ & 47.6 & - \\
\hline
\end{tabular}

Note: Alcohol use was recorded as consumption of at least one standard alcoholic drink per day.

LDL-C, low-density lipoprotein cholesterol; HDL-C, high-density lipoprotein cholesterol; BMI, body mass index; CD4, cluster of differentiation 4; HIV, human immunodeficiency virus; SD, standard deviation. 


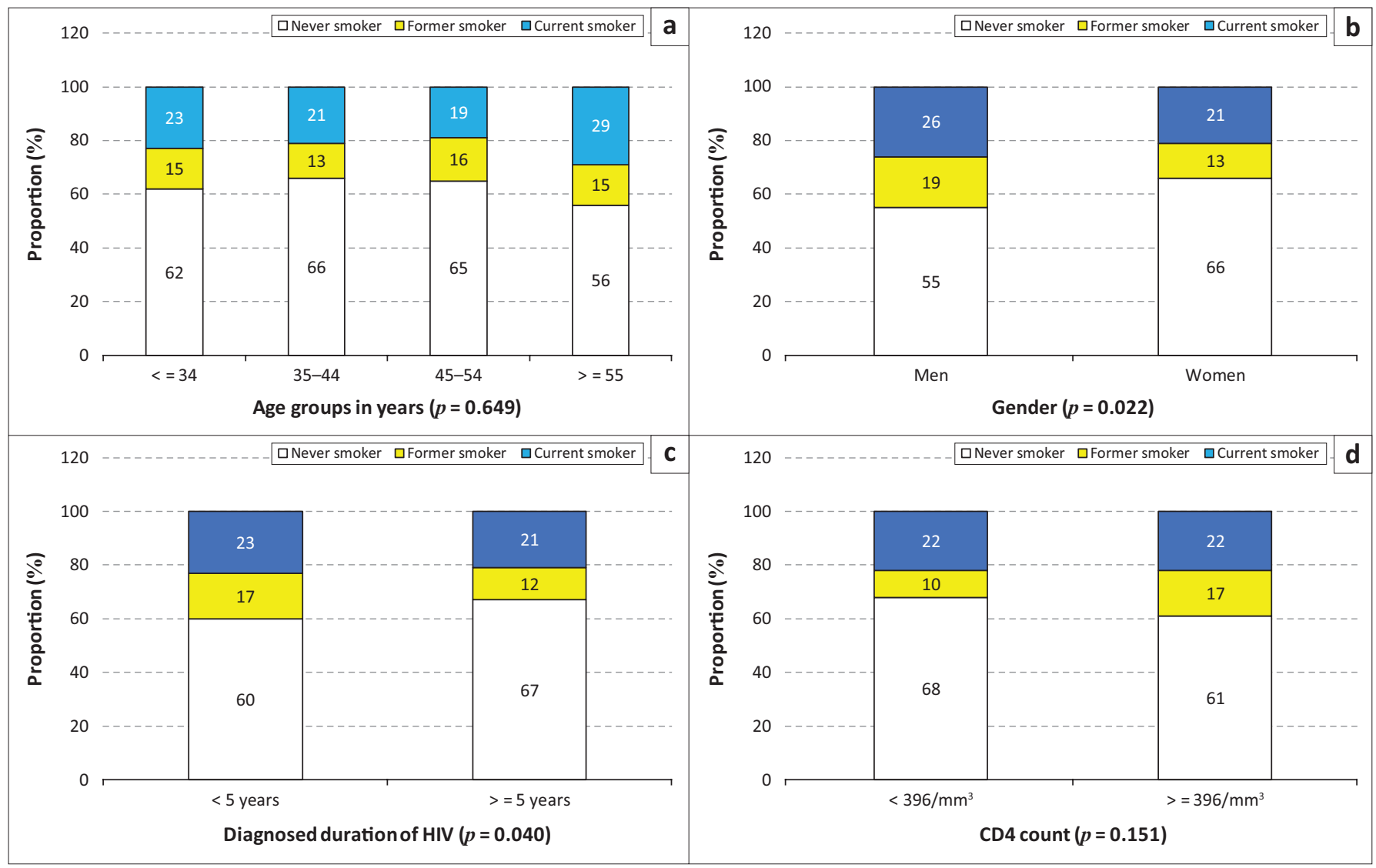

CD4, cluster of differentiation 4; HIV, human immunodeficiency virus.

FIGURE 1: Smoking status in different subgroups defined by (a) age, (b) gender, (c) known duration of human immunodeficiency virus infection and (d) cluster of differentiation 4 count.

by age category $(p=0.649)$. Smoking status was also marginally related to the known duration of HIV infection $(p=0.040)$ but not the CD4 count $(p=0.151)$ (Figure 1$)$.

Exposure to second-hand smoke was high with significantly higher rates in women (58.8\%) compared with men (44.8\%) $(p=0.001)$ (Table 1). The use of smokeless tobacco products was low, at $<3 \%$ for any sub-category, with no significant differences by gender or smoking status.

The median duration of diagnosed HIV infection was 6 years in current smokers, 5 years in non-smokers and 4 years in former smokers $(p=0.020)$. There were no significant differences in the median CD4 counts by smoking status. In age- and gender-adjusted logistic regression models, none of the general and HIV-predictive characteristics was associated with current smoking (Table 2).

Data on serum cotinine were available for 751 participants. About a quarter of these participants had serum cotinine levels $>100 \mathrm{mg} / \mathrm{mL}$, indicating exposure to tobacco smoke. Prevalence of high serum cotinine levels was similar across smoking status (current smokers: $28.5 \%$, former smokers: 25.9\% and never smokers: $23.1 \%)(p=0.564)$ and did not differ between men and women $(p=0.940)$, between those above and below median duration of diagnosed HIV infection $(p=0.681)$ and between those above and below median CD4 count ( $p=0.505$ ) (Figure 2$)$.
Figure 3 shows the cross-classification of smoking exposure by self-reports and serum cotinine levels, revealing the lack of agreement between the two classification methods (kappa $=-0.014, p=0.488)$. Among the 751 participants with data available on serum cotinine levels, 158 (21.0\%) were current smokers based on self-reports, 108 (14.4\%) were former smokers, and 485 (64.6\%) had never smoked. Among current smokers based on self-reports, 95 (60.1\%) had cotinine levels lower than $10 \mathrm{ng} / \mathrm{mL}$, indicative of low tobacco exposure, while $45(28.5 \%)$ had cotinine levels above $100 \mathrm{ng} / \mathrm{mL}$, indicative of moderate-to-heavy smoking. Among those who had never smoked, 300 (61.9\%) had no exposure to tobacco based on cotinine levels, while 112 (23.1\%) had cotinine levels compatible with moderate-toheavy smoking (Figure 3).

\section{Discussion}

Our data show that over one in five PLWHA currently smoke tobacco, with men being more likely to do so than women and with no indication that smoking habits were influenced either by the duration or by the time since HIV diagnosis and awareness of the nadir CD4 count. Furthermore, over half of the study samples (including those who had never smoked) were exposed to second-hand smoke, with such exposure being higher in women. For participants with data available on serum cotinine concentrations, about a quarter (including among self-declared never-smokers) had cotinine concentrations indicative of moderate-to-heavy tobacco 
TABLE 2: Logistic regression for the associations with current smoking in human immunodeficiency virus-infected patients.

\begin{tabular}{|c|c|c|}
\hline Variables & Adjusted OR & $p$ \\
\hline Age & $0.99[0.97-1.01]$ & 0.200 \\
\hline Gender & - & 0.229 \\
\hline Male patients & 1.00 & - \\
\hline Female patients & $1.27[0.86-1.89]$ & - \\
\hline Education & - & - \\
\hline$\leq$ Grade 12 & 1.00 & - \\
\hline$>$ Grade 12 & $1.30[0.87-1.93]$ & 0.298 \\
\hline Employment status & - & 0.452 \\
\hline Employed & 1.00 & - \\
\hline Unemployed & $0.72[0.47-1.10]$ & - \\
\hline Pensioners & $0.87[0.41-1.85]$ & - \\
\hline Other & $1.02[0.65-1.61]$ & - \\
\hline Marital status & - & 0.139 \\
\hline Married & 1.00 & - \\
\hline Never married & $1.33[0.87-1.96]$ & - \\
\hline Divorced or separated & $1.07[0.58-1.96]$ & - \\
\hline Widowed & $0.63[0.30-1.36]$ & - \\
\hline Smokeless tobacco smoking & $5.46[0.72-41.73]$ & 0.102 \\
\hline Household tobacco & $0.93[0.66-1.30]$ & 0.675 \\
\hline Alcohol use & $0.84[0.60-1.19]$ & 0.331 \\
\hline $\mathrm{BMI}$ in $\mathrm{kg} / \mathrm{m}^{2}$ & - & 0.299 \\
\hline Normal BMI < 25 & 1.00 & - \\
\hline Overweight or obese $\geq 25$ & $0.21[0.84-1.76]$ & - \\
\hline Current tuberculosis & $1.07[0.77-1.50]$ & 0.685 \\
\hline Duration of HIV+ diagnosis & - & 0.627 \\
\hline$<$ Median of 5 years & 1.00 & - \\
\hline$\geq$ Median of 5 years & $1.09[0.77-1.54]$ & - \\
\hline CD4+ count in cells $/ \mathrm{mm}^{3}$ & - & 0.954 \\
\hline$\geq$ Median of 396 cells $/ \mathrm{mm}^{3}$ & 1.00 & - \\
\hline$<$ Median of 396 cells $/ \mathrm{mm}^{3}$ & $0.98[0.60-1.62]$ & - \\
\hline
\end{tabular}

smoke exposure. Altogether, our findings suggest that despite the frequent contact of PLWHA with the health system, multiple opportunities had been missed to address the harmful effects of smoking or implement smoking cessation programmes.

Current estimates of smoking habits in the South African population are, in general, based on the 2012 SANHANES ${ }^{18}$ and the 2016 South African Demographic Health Survey (SADHS). ${ }^{3}$ According to the SANHANES, 20.8\% (32.8\% in men and $10.1 \%$ in women) of the general population ever smoked (which include current and former smokers) with $38.5 \%$ in the Western Cape province. Furthermore, about twothirds of participants had detectable cotinine in the blood, suggesting recent exposure to cigarette smoking. In the 2016 SADHS, $37 \%$ of men and $8 \%$ of women aged 15 years and above reported currently smoking tobacco products regularly or occasionally. Equivalent figures for the Western Cape province were $43 \%$ and $26 \%$. The prevalence of smoking in our sample, therefore, seems to be generally in line with recent estimates in the general population at the national level.

Few other studies reported smoking habits among PLWHA in SA. In a sample of 1210 PLWHA in Klerksdorp, Elf and coworkers ${ }^{20}$ found a $34 \%$ prevalence of ever-smokers, with rates being higher in men than in women, in line with our findings.
In an earlier study in a much smaller sample, Waweru and coworkers reported prevalence rates of $15 \%$ (men vs. women: $23.2 \%$ vs. $7.4 \%$ ) for current smoking in Johannesburg. ${ }^{21}$ Studies from other African countries suggest rates of smoking in PLWHA lower than those reported in SA; likely reflecting the relatively lower overall prevalence of smoking in the general population in these countries. ${ }^{22,23}$ In an analysis of Demographic Health Survey data from 27 low- and middle-income countries including 24 African countries (excluding SA), the overall prevalence of tobacco smoking in PLWHA across African countries was $24.2 \%$ in men (ranging from $9.7 \%$ in Ethiopia to $54.8 \%$ in The Gambia) and $1.0 \%$ in women (ranging from $0 \%$ in 11 countries to $4.4 \%$ in Gabon). ${ }^{24}$ Across these surveys, the risk ratio (RR) comparing the prevalence of smoking in people with versus without HIV was in favour of a $47 \%$ (male) and $87 \%$ (female) relatively higher prevalence in PLWHA. In about half of the studies, however, the confidence interval around RR generally crossed the unity, indicating no significant difference. ${ }^{24}$ The male preponderance in smoking uptake in the general population has largely been described. This gender difference extends to PLWHA in some studies but narrows down (as in ours) or even disappears completely in some, suggesting an increased uptake of the habit in women. ${ }^{25}$

One observation from our study was the lack of agreement between self-reports and measured cotinine at ranking status for smoking exposure. Assuming that bias in selfreported status would tend to favour concealing current smoking as opposed to wrongly claiming such a status, applying cotinine levels selectively only in former or never smokers, would have identified nearly an additional $20 \%$ of the total samples who were likely current smokers. This would nearly double the proportion of current smokers, suggesting that the dependence on self-report alone is likely to underestimate the true magnitude of current smoking among PLWHA in care. This assumption, however, must be considered in the context of the validity of the cotinine cutoffs applied in our study.

The harmful effects of smoking in PLWHA have been largely described. ${ }^{26}$ Smoking-related health hazards seen in the general population are exacerbated in PLWHA, where smoking is also responsible for some harmful health effects that are specific to this vulnerable population. People living with HIV and AIDS who smoke are at high risk of cancers (including non-AIDS defining cancers), chronic obstructive pulmonary diseases (COPDs) and chest infections. There are suggestions that smoking can also limit the benefits of ART and decrease life expectancy even in the context of adequate viral suppression ${ }^{27}$; nevertheless, achieving smoking cessation in PLWHA is likely more challenging than in the general population. Successful and sustainable smoking strategies are therefore needed to mitigate the risk of adverse health outcomes in PLWHA.

Given the burden of cigarette smoking and its adverse health outcomes among HIV-positive patients, screening for smoking and support to quit should be integrated into HIV and AIDS treatment programmes. Currently, evidence exists 


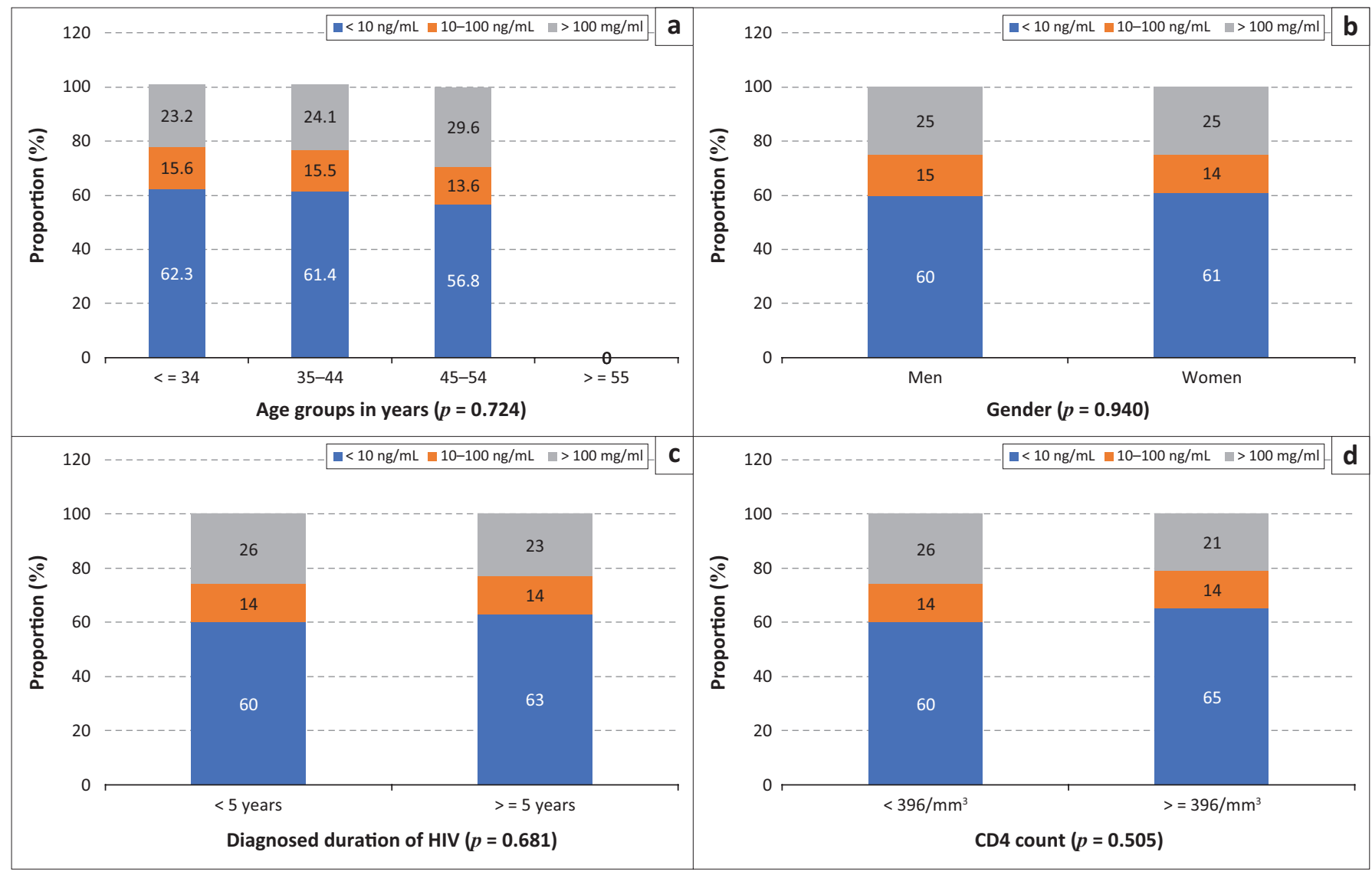

CD4, cluster of differentiation 4; HIV, human immunodeficiency virus.

FIGURE 2: Distribution of cotinine strata by (a) age group, (b) gender, (c) known duration of human immunodeficiency virus infection and (d) cluster of differentiation 4 count.

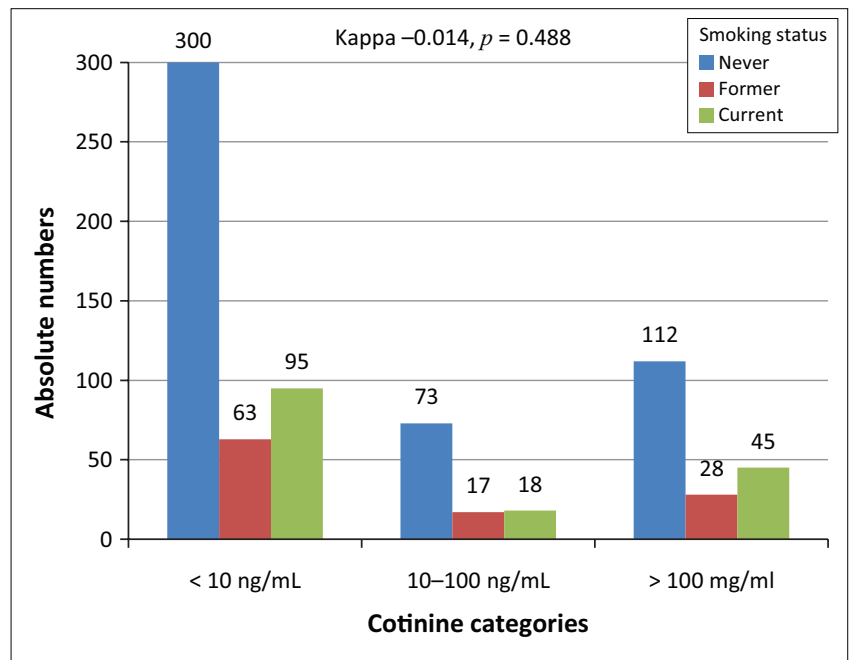

FIGURE 3: Agreement between self-reports and cotinine levels at ranking smoking status.

for both pharmacological and non-pharmacological interventions for smoking cessation, but evidence is needed on how they can best be implemented for smoking cessation in PLWHA in African countries. ${ }^{26,28}$ One recent qualitative review of smoking cessation interventions in PLWHA identified 32 publications reporting on 28 interventions. ${ }^{29}$ These studies essentially originated from western countries and the USA in particular. Thirteen of the interventions tested resulted in improved smoking cessation outcomes, with information and communication technologies and clinic- based interventions having the greatest potential to achieve smoking cessation among PLWHA. This is a significant observation considering that with regard to HIV care, PLWHA constitute a highly medicalised population, and are familiar with mHealth interventions in HIV care and monitoring. ${ }^{30}$ Another recent comparative meta-analysis concluded that compared with face-to-face, interventions mHealth interventions could better achieve smoking cessation in the short term in PLWHA. ${ }^{31}$ Besides the inadequate knowledge on the efficacy of interventions to achieve smoking cessation in PLWHA, other identified barriers hampering smoking cessation interventions in PLWHA include the scepticism of healthcare providers regarding certain interventions such as nicotine replacement, their unpreparedness to co-address smoking cessation during routine HIV care and other competing priorities. ${ }^{26}$ In the specific case of SA, economic, social or interpersonal and individual-level factors including stress have been suggested as barriers hindering smoking cessation in PLWHA. ${ }^{32}$

\section{Strengths and limitations}

This study has some limitations. Participants were recruited from only one province of SA and included predominantly women. Smoking assessment inconsistently collected data on the age at initiation (or cessation) of smoking, limiting our ability to assess the potential effect of HIV diagnosis on the adoption or cessation of smoking habits. Data were missing on HIV characteristics (CD4 count) in an important number 
of participants, limiting our statistical power for some subgroup analyses. The study included only PLWHA and therefore did not offer the opportunity of comparing estimates with those in the non-HIV-infected population. Our study also has some strengths including the relatively large and randomly selected sample, which increased the generalisability of our findings. We also had data on blood cotinine in about $90 \%$ of our sample, which allowed us to substantiate that self-reports alone likely misclassify smoking status, with nearly a quarter of those reporting never smoking, having blood cotinine levels compatible with current moderate-to-heavy smoking.

\section{Conclusion}

People living with HIV and AIDS in care have current tobacco smoking rates within the range of those found in the general population. These rates appear similar regardless of the known duration of HIV infection and status of disease control. This highlights the potential of missed opportunities or the challenges of co-addressing smoking cessation in PLWHA who are already in regular contact with the health system for the management of HIV and related co-morbidities. With the improved survival of PLWHA on ART and the emergence of NCDs as a new threat to the health of this population, proactively addressing smoking and other major NCD risk factors must become an integral part of the routine care of PLWHA.

\section{Acknowledgements}

The authors are grateful to Deborah Jonathan and Erica April from the SAMRC's NCD Research Unit, and their team, for the huge effort to collect data for this study.

\section{Competing interests}

The authors have declared that no competing interests exist.

\section{Authors' contributions}

A.P.K. conceived the study and acquired the funding. A.D.V. operationalised and supervised data collection in collaboration. M.M. and A.P.K. analysed the data and drafted the manuscript. N.P. and M.F. critically reviewed the data and revised the manuscript. All co-authors approved the submission. A.P.K. is the guarantor.

\section{Funding information}

This study was supported by Grand Challenges Canada, through the Global Alliance on Chronic Diseases initiative (Hypertension Grant \#0169-04).

\section{Data availability statement}

Data are available upon request from the corresponding author.

\section{Disclaimer}

The views and opinions expressed in this article are those of the authors and do not necessarily reflect the official policy or position of any affiliated agency of the authors.

\section{References}

1. Drope J, Schluger NW, Cahn Z, et al. The tobacco atlas: American Cancer Society and vital strategies. 6th ed. Atlanta, GA: American Cancer Society; 2018.

2. Groenewald $P$, Vos $T$, Norman $R$, et al. Estimating the burden of disease attributable to smoking in South Africa in 2000. S Afr Med J. 2007;97(8 Pt 2):674-681.

3. National Department of Health (NDoH), Statistics South Africa (Stats SA), South African Medical Research Council (SAMRC), ICF. South Africa demographic health survey 2016. Pretoria: NDoH, Stats SA, SAMRC, and ICF; 2019.

4. Crothers K, Goulet JL, Rodriguez-Barradas MC, et al. Impact of cigarette smoking on mortality in HIV-positive and HIV-negative veterans. AIDS Educ Prev. 2009;21(3 Suppl):40-53. https://doi.org/10.1521/aeap.2009.21.3_supp.40

5. Davies T-L, Gompels M, Johnston S, Bovill B, May MT. Mind the gap: Difference between Framingham heart age and real age increases with age in HIV-positive individuals - A clinical cohort study. BMJ Open. 2013;3(10):e003245. https://doi. org/10.1136/bmjopen-2013-003245

6. Broom J, Sowden D, Williams M, Taing K, Morwood K, McGill K. Moving from vira suppression to comprehensive patient-centered care: The high prevalence of comorbid conditions and health risk factors in HIV-1-infected patients in Australia. $J$ Int Assoc Physicians AIDS Care (Chic). 2012;11(2):109-114. https://doi. org $/ 10.1177 / 1545109711418832$

7. Tesoriero JM, Gieryic SM, Carrascal A, Lavigne HE. Smoking among HIV positive New Yorkers: Prevalence, frequency, and opportunities for cessation. AIDS Behav. 2010;14:824-835. https://doi.org/10.1007/s10461-008-9449-2

8. Statistics South Africa. Mid-year population estimates, 2019. In: Statistics South Africa, editor. Pretoria: Statistics South Africa; 2019

9. Mayosi BM, Lawn JE, Van Niekerk A, et al. Health in South Africa: Changes and challenges since 2009. Lancet. 2012;380(9858):2029-2043. https://doi. org/10.1016/S0140-6736(12)61814-5

10. May MT, Gompels M, Delpech V, et al. Impact on life expectancy of HIV-1 positive individuals of CD4+ cell count and viral load response to antiretroviral therapy. AIDS. 2014;28(8):1193-1202. https://doi.org/10.1097/QAD.0000000000000243

11. Phillips AN, Neaton J, Lundgren JD. The role of HIV in serious diseases other than AIDS. AIDS. 2008;22(18):2409-2418. https://doi.org/10.1097/QAD. Ob013e3283174636

12. Lifson AR, Neuhaus J, Arribas JR, et al. Smoking-related health risks among persons with HIV in the strategies for management of antiretroviral therapy clinical trial. Am J Public Health. 2010;100(10):1896-1903. https://doi. org/10.2105/AJPH.2009.188664

13. Mutemwa M, Peer N, De Villiers A, et al. Prevalence, detection, treatment, and control of hypertension in human immunodeficiency virus (HIV)-infected patients attending HIV clinics in the Western Cape province, South Africa. Medicine. 2018;97(35):e12121. https://doi.org/10.1097/MD.0000000000012121

14. STEPS W. A framework for surveillance: The WHO STEPwise approach to surveillance of noncommunicable diseases (STEPS). Geneva: World Health Organization; 2003.

15. Nguyen KA, Peer N, De Villiers A, et al. The distribution of obesity phenotypes in HIV-infected African population. Nutrients. 2016;8(6):299. https://doi. org/10.3390/nu8060299

16. Balhara YP, Jain R. A receiver operated curve-based evaluation of change in sensitivity and specificity of cotinine urinalysis for detecting active tobacco use. Cancer Res Ther. 2013;9(1):84-89. https://doi.org/10.4103/0973-1482.110384

17. Duque A, Martínez PJ, Giraldo A, et al. Accuracy of cotinine serum test to detect the smoking habit and its association with periodontal disease in a multicente study. Med Oral Patol Oral Cir Bucal. 2017;22(4):e425-e431. https://doi. org/10.4317/medoral.21292

18. Shisana O, Labadarios D, Rehle T, et al. The South African National Health and Nutrition Examination Survey, 2012: SANHANES-1: The health and nutritional status of the nation. Paarl: HSRC Press; 2013.

19. World Health Organization. Obesity: Preventing and managing the global epidemic: Report of a WHO consultation. WHO technical report series. Geneva: World Health Organization; 2000.

20. Elf JL, Variava E, Chon S, et al. Prevalence and correlates of smoking among people living with HIV in South Africa. Nicotine Tobacco Res. 2017;20(9):1124-1131. https://doi.org/10.1093/ntr/ntx145

21. Waweru P, Anderson R, Steel H, Venter WD, Murdoch D, Feldman C. The prevalence of smoking and the knowledge of smoking hazards and smoking cessation strategies among HIV-positive patients in Johannesburg, South Africa. S Afr Med J. 2013;103(11):858-860. https://doi.org/10.7196/SAMJ.7388

22. Jaquet $A$, Ekouevi DK, Aboubakrine $M$, et al. Tobacco use and its determinants in HIV-infected patients on antiretroviral therapy in West African countries. Int Tuberc Lung Dis. 2009;13(11):1433-1439.

23. Iliyasu Z, Gajida AU, Abubakar IS, Shittu O, Babashani M, Aliyu MH. Patterns and predictors of cigarette smoking among HIV-infected patients in northern Nigeria. Int J STD AIDS. 2012;23(12):849-852. https://doi.org/10.1258/ ijsa.2012.012001 
24. Mdege ND, Shah S, Ayo-Yusuf OA, Hakim J, Siddiqi K. Tobacco use among people living with HIV: Analysis of data from Demographic and Health Surveys from
28 low-income and middle-income countries. Lancet Glob Health. 2017;5(6): 28 low-income and middle-income countries. Lancet Glob
e578-e592. https://doi.org/10.1016/S2214-109X(17)30170-5

25. Smith PH, Zhang J, Weinberger AH, Mazure CM, McKee SA. Gender differences in the real-world effectiveness of smoking cessation medications: Findings from the 2010-2011 Tobacco use supplement to the current population survey. Drug Alcohol Depend. 2017;178:485-491. https://doi.org/10.1016/j. drugalcdep.2017.05.046

26. Giles ML, Gartner C, Boyd MA. Smoking and HIV: What are the risks and what harm reduction strategies do we have at our disposal? AIDS Res Ther. 2018;15(1):26. https://doi.org/10.1186/s12981-018-0213-z

27. Mdodo R, Frazier EL, Dube SR, et al. Cigarette smoking prevalence among adults with HIV compared with the general adult population in the United States: Crosssectional surveys. Ann Intern Med. 2015;162(5):335-344. https://doi.org/10.7326/ M14-0954
28. Ledgerwood DM, Yskes R. Smoking cessation for people living with HIV/AIDS: A literature review and synthesis. Nicotine Tob Res, 2016;18(12):2177-2184. https://doi.org/10.1093/ntr/ntw126

29. Mann-Jackson L, Choi D, Sutfin EL, et al. A qualitative systematic review of cigarette smoking cessation interventions for persons living with HIV. J Cancer Educ. 2019;34(6):1045-1058. https://doi.org/10.1007/s13187-019-01525-2

30. Cooper V, Clatworthy J, Whetham J, Consortium E. mHealth interventions to support self-management in HIV: A systematic review. Open AIDS J. 2017;11: 119-132. https://doi.org/10.2174/1874613601711010119

31. Uthman OA, Nduka CU, Abba M, et al. Comparison of mHealth and face-to-face interventions for smoking cessation among people living with HIV: Meta-analysis. JMIR Mhealth Uhealth. 2019;7(1):e203. https://doi.org/10.2196/mhealth.9329

32. Krishnan N, Gittelsohn J, Ross A, et al. Qualitative exploration of a smoking cessation trial for people living with HIV in South Africa. Nicotine Tob Res. 2018;20(9):1117-1123. https://doi.org/10.1093/ntr/ntx139 